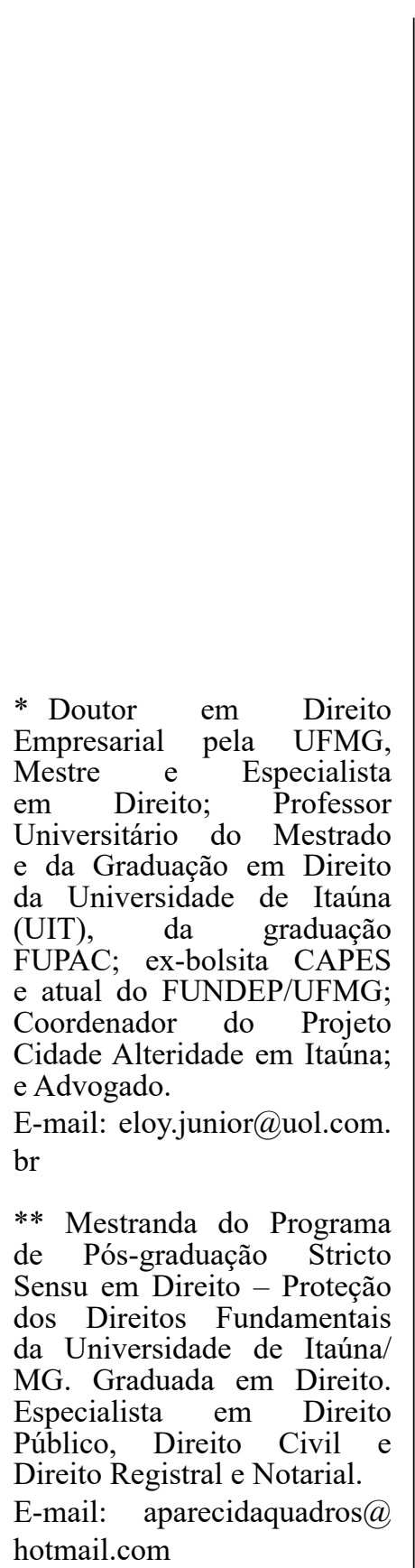

* Doutor em Direito em Direito; Professor Universitário do Mestrado e da Graduação em Direito da Universidade de Itaúna (UIT), da graduação FUPAC; ex-bolsita CAPES Cidade Alteridade em Itaúna; e Advogado.

E-mail: eloy.junior@uol.com.

de Pós-graduação Stricto Sensu em Direito - Proteção dos Direitos Fundamentais da Universidade de Itaúna/ MG. Graduada em Direito. Especialista em Direito Público, Direito Civil E-mail: aparecidaquadros@ hotmail.com

\section{A Implantação de Políticas Públicas pela Solução Judicial Dialogada}

\author{
The Implementation Of Public Policies In Conflict \\ RESOLUTION
}

\section{Eloy Pereira Lemos Junior* Aparecida Dutra de Barros Quadros**}

Como citar: LEMOS JUNIOR, Eloy Pereira; QUADROS, Aparecida Dutra de Barros. A implantação de políticas públicas pela solução judicial dialogada. Revista do Direito Público, Londrina, v. 14, n. 3, p. 11-34, dez. 2019. DOI: 10.5433/24157-108104-1.2019v1 4n3p. 11. ISSN: 1980-511X

Resumo: As decisões judiciais para cumprimento de Políticas Públicas consubstanciadas em obrigações de fazer não encontra efetividade na execução forçada. O Estado Democrático de Direito requer vias alternativas para a solução das controvérsias resultantes de colisões de direitos e interesses fundamentais. A ebulição de necessidades de $2^{\mathrm{a}}$ e $3^{\mathrm{a}}$ dimensões que clamam pela via das tutelas coletivas requer ações prestacionais eficientes. A solução negociada dialogada para implementação de políticas públicas se afigura possível em face das normas fundamentais e de aplicação do direito processual constitucional reordenado com os valores e princípios estabelecidos no ordenamento jurídico. A metodologia empregada na elaboração do presente artigo foi dedutivo-hipotética por meio da pesquisa teórico-bibliográfica e documental.

Palavras-chave: Controle jurisdicional. Direitos fundamentais. Políticas públicas. Vias alternativas. Solução judicial negociada.

\begin{abstract}
Judicial decisions complying with Public Policies are inefficient as they are not currently enforceable obligations. Furthermore, the democratic rule of law requires alternative ways of conflict resolution resulting from the many collisions of fundamental human rights and interests. Both 2nd and 3rd dimensions call for collective tutelage, which, essentially, requires efficient government
\end{abstract}


action. Nonetheless, dispute resolution should implement public policies considering fundamental norms and the application of constitutional procedural law with the values and principles already established in Brazil's legal order. This paper's methodology utilized the deductive-hypothetical with theoretical-bibliographic literature review.

Keywords: Jurisdictional control. Fundamental rights. Public policy. Alternative routes. Legal settlement. 


\section{INTRODUÇÃO}

O Estado Democrático de Direito se acha caracterizado pelo conjunto de princípios e regras irradiantes da Constituição e, uma vez entendido como integridade, comporta um sentido amplo sendo um dos instrumentos essenciais para o exercício do Poder e legitimação das funções estatais.

Buscando a conceituação de Poder esse pode ser traduzida na relação de conformação, legitimidade e controle entre aqueles que o detêm e aqueles que são os seus destinatários, sendo que essa relação tem bases políticas, sociais, culturais, religiosas e econômicas. Destarte, o Estado é o exercício do poder político legitimado por essa relação e centrado nos aspectos jurídicos que conformam sua atuação com vistas a garantir liberdade e proteção dos direitos aos destinatários.

Por essa compreensão tem-se o Poder exercido legitimamente por meio dos organismos estatais, os quais se valem do Processo, que uma vez estruturado como instrumento jurídico constitucional se apresenta como veículo de transformação da realidade social e, estará presente nas diversas funções do Estado a fim de possibilitar a efetiva tutela de proteção e fomento de direitos.

É necessário ressaltar que na concretização de direitos fundamentais frente às tensões entre as normas constitucionais, o Estado na execução das atividades administrativas de implantação de meios para atingir os fins públicos estabelecido pelo legislador, por vezes se vê envolvido em conflitos em face dos preceitos fundamentais no âmbito das relações jurídicas, levando então o Judiciário a atuar no controle e fiscalização da implantação das promessas constitucionais.

No Direito Democrático Contemporâneo, sob a perspectiva do Direito Processual Constitucional, a jurisdição deve ser entendida como possibilidade de inserir o sujeito no sistema de direitos. Dessa forma o processo como defesa e garantia de direitos materializado pelo acesso à justiça se acha reordenado, disciplinado e interpretado conforme os valores e as normas fundamentais estabelecidos na Constituição da República Federativa do Brasil de 1988 (CRFB), passando desta forma a ser imperioso a realização do processo plurilateral, negociado e com a participação ativa e dialogada dos interessados e do órgão jurisdicional.

O Devido Processo Constitucional oferece os instrumentos jurídicos necessários para o cumprimento da sua tarefa e ao mesmo tempo fornece os meios convenientes para a solução das tensões geradas pelos conflitos entre princípios colidentes diante de políticas públicas não implantadas ou mesmo ineficientes.

Com essas considerações objetiva-se por intermédio da presente pesquisa discorrer sobre a via alternativa do processo judicial enquanto ressignificado pelo Direito Processual Constitucionalizado, que se desponta como instrumento eficaz para a garantia da supremacia da Constituição na proteção de direitos fundamentais. Dessa forma busca-se a efetivação de uma cultura da solução consensual de conflitos, vez que a força irradiante da Constituição requer os ditames do bom senso, da consensualidade e da negociabilidade entre as partes, pugnando pela participação dialogada, flexibilização das amarras processuais e das técnicas administrativas, 
podendo ser ajustado às especificidades da causa, convencionando-se sobre ônus, poderes, faculdades e deveres processuais.

Nesse contexto, sob a premissa de que o direito de ação enquanto instrumento de defesa e garantia de direitos previsto no capítulo de Direitos Fundamentais da Constituição é mais amplo e requer também uma nova leitura por meio do devido processo constitucional, procura-se demonstrar que a execução judicial forçada não é o único caminho para a prestação da jurisdição. Contudo não se pode prescindir das normas fundamentais do processo pautado pelos princípios de reordenação e interpretação dos valores constitucionais.

Assim, com o propósito de responder ao problema apresentado, a presente pesquisa subdivide-se em quatro partes, além da introdução e considerações finais: a) o primeiro capítulo, em que se busca compreender a dupla dimensão dos direitos fundamentais e sua eficácia nas relações jurídicas; b) no segundo, em que se discute a centralidade protagonizada pelo Judiciário; c) nesse terceiro capítulo aborda-se as vias alternativas para defesa e proteção dos direitos fundamentais; d) no quarto capítulo procura-se demostrar a possiblidade da implantação da solução judicial dialogada para o cumprimento de decisões concernentes em obrigações da fazer contra a Fazenda Pública.

Trata-se de uma pesquisa de caráter descritivo pela qual busca-se realizar um estudo bibliográfico e documental sobre o Processo ressignificado e as alternativas para a resolução consensual de conflitos no âmbito judicial com competência para realização de acordos, transações, flexibilizações de prazos, definição de calendários de cumprimentos das obrigações e a participação ativa no planejamento e execução da política pública requerida em juízo, cuja prestação jurisdicional irá pautar pela boa-fé, colaboração, cooperação e lealdade entre as partes no processo, visto que no Estado Democrático de Direito está a pessoa humana em seus direitos e deveres a ocupar a centralidade do ordenamento, sendo esse o norte das finalidades estatais.

A pesquisa empreenderá uma investigação propositiva, visto que objetiva apresentar propostas para o debate científico visando discutir soluções judiciais negociadas como via alternativa para garantia e proteção dos direitos fundamentais exercido por meio do controle judicial de políticas públicas.

\section{A DUPLA DIMENSÃO DOS DIREITOS FUNDAMENTAIS}

O Brasil experimenta situações paradoxais, iniciando pela passagem do Estado Liberal para o Estado Social na luta por direitos e a evolução de suas conquistas, na qual na fase do liberalismo exigia-se uma atuação negativa da administração com foco na preservação de direitos e contenção dos poderes visando a redução da influência estatal na vida dos indivíduos.

O Estado Liberal, nos pilares do iluminismo e da idade moderna, firmou um modelo para garantia da liberdade do exercício dos direitos civis e políticos em contraposição ao Estado Absolutista que imperava na idade média, definindo nessa órbita a autonomia individual com o protagonismo do direito privado, onde não se aceitava a interferência estatal e exigia-se a subsunção 
do poder público ao império da lei, inaugurando assim a conquista de direitos de $1^{\mathrm{a}}$ dimensão.

$\mathrm{Na}$ evolução dos direitos humanos, sendo esses históricos e universais, mas não definitivos, demandou-se a luta pelos direitos de segunda geração em face da necessidade de atendimento prestacional por parte do Estado, cujo destinatário do poder requeria maior atenção para a redução das desigualdades materiais entre os indivíduos diante do descompasso do capitalismo e, dessa forma, se viu o agigantamento da função executiva e a hipertrofia do Estado-Administração, caracterizando o Estado Social, no qual figurava o cidadão-cliente com predomínio daAdministração sobre a Política e destaque do direito público sobre o direito privado.

Comabusca ampliação dos direitos humanos assistiu-se o fenômeno do constitucionalismo, em especial no pós grandes guerras mundiais, onde no século XX pode-se destacar a Constituição do México em 1917 e a Constituição da Alemanha de 1919 em Weimar (PINHEIRO, 2006), nas quais positivou-se os direitos fundamentais e cujos documentos normativos inspiraram diversos Organismos Estatais a elaborarem seus textos constitucionais a exemplo do Estado Brasileiro, e, na sequência emergiram necessidades de proteção dos direitos fundamentais e a manutenção da vida na Terra passou a ser centro das discussões jurídicas ao que se denominou direitos de terceira dimensão ou geração.

Em face a ebulição natural de uma sociedade em evolução surge o neoconstitucionalismo pelo qual se reconhece a superioridade do texto constitucional e a eficácia irradiante dos parâmetros constitucionais na concretização das premissas de justiça social e construção de uma sociedade livre e solidária.

Nesse descortino rompe-se com o Estado de Direito do positivismo e volta-se para o Estado Democrático de Direito em uma versão pós-positivista, onde as prescrições constitucionais passam a possuir normatividade consubstanciada em regras ou princípios irradiantes e com força conformadora.

Os direitos fundamentais, com o fenômeno do pós-positivismo ou neoconstitucionalismo, passaram a experimentar uma ampliação dual de sua efetividade, pois ao mesmo tempo em que são possuidores de eficácia em uma dimensão proibitiva, voltada para o legislador a fim de que se abstenha de editar leis violadoras de direitos fundamentais, também experimentam uma dimensão positiva, de forma que esse mesmo legislador implemente os direitos fundamentais; porém agora com a superação da summadivisio clássica de direito público e direito privado e a efetivação da nova summadivisio constitucionalizada de direito coletivo e direito individual (ALMEIDA, 2008), emergindo, portanto a dimensão coletiva dos metainteresses ou direitos fundamentais que passa a figurar ao lado dos direitos ou interesses individuais.

Sobre direitos transindividuais e direitos individuais é oportuno trazer as especificidades que revelam cada qual, onde na categoria de direitos coletivos latu sensu situam-se os direitos ou interesses difusos, coletivos, individuais homogêneos e individuais indisponíveis. Já os direitos individuais propriamente ditos são os tutelados pelas vias comuns individuais e protegem os direitos e interesses individualmente considerados.

Os direitos ou interesses difusos são trans-meta-supra individuais, isto é, aqueles que 
abrangem um número indeterminado de pessoas, não têm como titular um único indivíduo, vez que os titulares são indeterminados ou indetermináveis, mas ligadas por uma situação de fato a exemplo de um dano ambiental, portanto não há uma relação jurídica entre os envolvidos. Contudo o direito difuso é indivisível e não pode ser fracionado, pois como lesados encontra- toda a coletividade e mesmo que possam ser indicados, porque são finitos, a sua individualização é trabalhosa e despropositada e que em nada altera a situação fática.

Os interesses ou direitos coletivos são também transindividuais, mas representados por uma coletividade e, portanto, indivisíveis, pois todos daquele grupo, classe ou categoria suportam os mesmos efeitos. Ademais essa coletividade é representada por pessoas que estão ligadas entre si ou com a parte contrária por uma relação jurídica base e não é o sujeito individualmente considerado, mas sim o grupo de sujeitos que a priori eram indeterminados, mas que são determináveis, sendo então individualizados os sujeitos lesados a exemplo do grupo de pessoas encarceradas vulnerabilizadas pela ausência de condições dignas de ser humano.

Já nos direitos individuais homogêneos o titular não é a coletividade ou uma comunidade, mas o direito é dos indivíduos e não é indivisível, pois que é decomponível entre cada um, mas em razão da origem comum, fática ou jurídica são acidentalmente coletivos, a exemplo dos direitos do consumidor, como se depreende do artigo 81, parágrafo único, inciso III da Lei no 8.078/90 Código de Defesa do Consumidor (BRASIL, 1990). ${ }^{1}$

Nesse entendimento é a lição de Teori Albino Zavascki:

Já os direitos individuais homogêneos são, simplesmente, direitos subjetivos individuais. A qualificação de homogêneos não altera nem pode desvirtuar essa sua natureza. É qualificativo utilizado para identificar um conjunto de direitos subjetivos individuais ligados entre si por uma relação de afinidade, de semelhança, de homogeneidade, o que permite a defesa coletiva de todos eles. Para fins de tutela jurisdicional coletiva, não faz sentido, portanto, sua versão singular (um único direito homogêneo), já que a marca da homogeneidade supõe, necessariamente, uma relação de referência com outros direitos individuais assemelhados. Há, é certo, nessa compreensão, uma pluralidade de titulares, como ocorre nos direitos transindividuais; porém, diferentemente desses (que são indivisíveis e seus titulares são indeterminados), a pluralidade, nos direitos individuais homogêneos não é somente dos sujeitos (que são indivíduos determinados), mas também do objeto material, que é divisível e pode ser decomposto em unidades autônomas, com titularidade própria. [...] Quando se fala, pois, em "defesa coletiva" ou em "tutela coletiva" de direitos homogêneos, o que se está qualificado como coletivo não é o direito material tutelado, mas sim o modo de tutelá-lo, o instrumento de sua defesa (ZAVASCKI, 2017, p. 40).

Os direitos individuais indisponíveis, por sua vez, são aqueles em que o interesse é individual e que podem ter até mesmo um único sujeito titular do direito material lesado, mas diante da sua hipossuficiência, ou hipervulnerabilidade, o Ministério Púbico se vê legitimado a

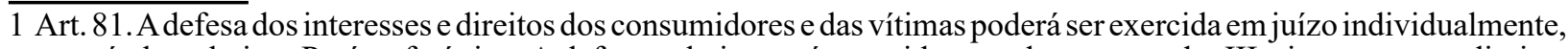
ou a título coletivo. Parágrafo único. A defesa coletiva será exercida quando se tratar de: III - interesses ou direitos individuais homogêneos, assim entendidos os decorrentes de origem comum.
} 
ingressar em juízo com os instrumentos do microssistema coletivo com vistas ao acesso imediato desse indivíduo a direitos fundamentais relacionados com o mínimo existencial para a manutenção da dignidade humana, a exemplo do Estatuto da Criança e do Adolescente - Lei no 8.069/90, art. 201, V ( BRASIL, 1990)² e o Estatuto do Idoso - Lei $n^{\circ}$ 10.741, artigo 74, I (BRASIL, 2003). ${ }^{3}$

Sobre o fenômeno da irradiação dos direitos fundamentais coletivos e individuais, objetivando-se a eficácia plena das normas constitucionais, ainda que não exista normas infraconstitucionais são essas as lições de Luiz Roberto Barroso:

Nesse ambiente, a Constituição passa a ser não apenas um sistema em si - com a sua ordem, unidade e harmonia - mas também um modo de olhar e interpretar todos os demais ramos do Direito. Este fenômeno, identificado por alguns autores como filtragem constitucional, consiste em que toda a ordem jurídica deve ser lida e apreendida sob a lente da Constituição, de modo a realizar os valores nela consagrados. Como antes já assinalado, a constitucionalização do direito infraconstitucional não tem como sua principal marca a inclusão na Lei Maior de normas próprias de outros domínios, mas, sobretudo, a reinterpretação de seus institutos sob uma ótica constitucional. À luz de tais premissas, toda interpretação jurídica é também interpretação constitucional. Qualquer operação de realização do direito envolve a aplicação direta ou indireta da Lei Maior (BARROSO, 2007, p. 20-21).

Com o fenômeno da constitucionalização do direito irradiando princípios e valores consagrados na Carta Constitucional para todos os ramos do saber, elevou-se a dignidade humana ao status de fundamento republicano e se conferiu à pessoa humana a centralidade do ordenamento devendo todas as normas infra legais zelar pela sua defesa e proteção.

Dessa forma essa é a premissa do Estado Democrático de Direito Contemporâneo, que tem a Constituição como sua base hermenêutica e integradora, e justifica a releitura de todo o ordenamento com as lentes focadas à proteção do ser humano e defesa dos direitos fundamentais.

É inegável a relevância dos direitos fundamentais no ordenamento jurídico no Estado Democrático de Direito Contemporâneo, e sustentar a ineficácia é relegar a força normativa e irradiante das normas constitucionais. Portanto, uma vez reconhecido que são eles aplicáveis nas relações jurídicas de direito coletivo e de direito individual pela concepção dual dos direitos fundamentais, podendo-se afirmar que a visão dicotômica entre as esferas de direito público e de direito privado, não mais se coaduna com os valores democráticos de uma sociedade em evolução, visto que no constitucionalismo contemporâneo não há duas ordens jurídicas, mas tão somente uma única com dupla dimensão e que tem como norte a supremacia dos direitos fundamentais coletivos e individuais.

Destarte, a relação entre a administração e o particular não mais podem ser vistas como subordinação do interesse privado ao interesse público, pois o Estado-Administração ou o Estado-

2 Art. 201. Compete ao Ministério Público: V - promover o inquérito civil e a ação civil pública para a proteção dos interesses individuais, difusos ou coletivos relativos à infância e à adolescência, inclusive os definidos no art. $220, \S$ $3^{\circ}$ inciso II, da Constituição Federal.

3 Art. 74. Compete ao Ministério Público: I - instaurar o inquérito civil e a ação civil pública para a proteção dos direitos e interesses difusos ou coletivos, individuais indisponíveis e individuais homogêneos do idoso. 
Juiz que intervém na vida do cidadão deve rechaçar qualquer invocação genérica da preponderância do interesse público em sobreposição ao ser humano em sua dignidade e centralidade do ordenamento jurídico.

\section{A CENTRALIDADE PROTAGONIZADA PELO JUDICIÁRIO}

Sob o pálio da Constituição de 1988 (BRASIL, 1988) o Direito Brasileiro experimenta uma mutação em seu ordenamento e também no exercício da jurisdição, reconhecendo-se a força normativa de princípios com alta carga axiológica ao que se denominou de neoconstitucionalismo, conforme fora explicitado no tópico anterior, fato esse que coloca o judiciário na centralidade desse poder.

Destarte, pela CRFB de 1988, de onde se extrai direitos fundamentais de diversas dimensões e, frise-se, aos quais se conferiu aplicabilidade imediata como estabelece o seu art. $5^{\circ}$ $\S 1^{\circ}$, somado ao fortalecimento do Judiciário ao se consagrar a inafastabilidade da tutela judicial no mesmo artigo em seu inciso XXXV (BRASIL, 1988), privilegiou as decisões principiológicas e, portanto são judicializadas questões que não foram resolvidas pelo Poder Legislativo ou o foram de forma ineficiente, mas o certo é que grandes questões políticas, sociais, morais, econômicas, públicas ou privadas estão sendo decididas perante o Poder Judiciário e por isso tem-se que a judicialização é um fato.

Diante desse crescente acesso ao judiciário na busca da efetivação dos direitos fundamentais, para complementação ao debate destaca-se ainda o ativismo judicial, compreendendo-se esse como atitude do Poder Judiciário associada à participação ampla na implementação dos direitos fundamentais e que se contrapõe a autocontenção judicial. Contudo o acesso e a satisfação têm que ser proporcional ao limite existente e real, sob pena de se tornar insustentável, pois adverte Clayton Maranhão:

Assim, calha mencionar que correlativamente à era dos direitos mencionada por Norberto Bobbio, seguramente há um estado de perplexidade doutrinária e jurisprudencial concernente a um estado de insaciabilidade desses mesmos direitos, o que deve ser ponderado em tema de justiciabilidade das posições fundamentais no direito brasileiro[...] (MARANHÃO, 2010, p. 167).

O ativismo judicial é a escolha de um modo específico e proativo de interpretar a constituição por meio de expansão dos seus sentidos e do seu alcance. Trata-se de uma atitude mais intensa e expansiva do judiciário na concretização dos valores e dos fins constitucionais em face da forte densidade semântica dos princípios.

Ocorre que o Poder Judiciário, então ocupante da centralidade das funções estatais, em oposição à autocontenção judicial que se caracteriza como uma atitude mais conservadora, invade por vezes as esferas do Poder Executivo e do Poder Legislativo se projetando no cenário jurídico, político e administrativo em detrimento à especialização das funções do Estado, acarretando assim 
um processo autofágico dos poderes estatais.

José Luiz Bolzan de Morais assevera que a Constituição, enquanto documento jurídicopolítico, é um instrumento de segurança e legitimidade social, mas adverte que nos vemos em uma crise institucional sob a fórmula do neoconstitucionalismo e que repercute na própria funcionalidade do Estado onde assistimos a uma disputa intestina de poder e em cujo embate a centralidade é assumida pela função jurisdicional em afronta à separação e harmonia das funções estatais (MORAIS, 2011, p. 56).

Nessa perspectiva a Judicialização como fato e, na expressão cunhada por Morais e Brum, seu irmão siamês o ativismo judicial (MORAIS; BRUM, 2016, p. 65), podem contribuir para a evolução democrática das relações jurídicas por meio da interpretação do dinamismo da mutação social, pois seja via legislativa, judicial ou por meio da própria Administração Pública, novos contornos devem e precisam ser adotados para se amoldar a lei à vida, essa é a lógica inevitável da evolução da conquista dos direitos humanos.

\subsection{Os Filtros e a Inafastabilidade Do Acesso À Justiça}

A terminologia acesso à justiça é usualmente empregada como a finalidade básica do sistema jurídico pelo qual o cidadão possa reivindicar seus direitos e resolver os conflitos mediante a intervenção do Estado, mas também se traduz no funcionamento de um sistema acessível a todos, pelo qual se busca o acesso ao direito e não somente acesso judiciário, podendo ser então firmado como um direito fundamental que deve ser garantido pelas funções estatais na busca de se promover a igualdade material e jurídica.

Nessa ordem Sérgio Shimura (2007) assim se expressa:

A previsão abstrata de direitos substanciais fundamentais perde muito de seu sentido se não tiver ao seu dispor instrumentos eficazes de materializá-los em sua plenitude. Daí a imperiosa necessidade de se buscar o verdadeiro sentido da expressão "acesso à Justiça", sempre tendo com o norte o provimento jurisdicional mais próximo e rente possível daquela situação prevista no ordenamento (SHIMURA, 2007, p. 345).

A busca da igualdade e o equilíbrio entre a demanda e a prestação de serviço é o ponto central para a satisfação e efetividade na execução da atividade administrativa diante das promessas constitucionais do Estado do bem-estar social, pelo que é recorrente o surgimento de conflitos em decorrência das relações jurídicas travadas no cotidiano entre os Órgãos e Entidades da Administração e os administrados.

Nessa senda, para concretização de direitos fundamentais o Poder Judiciário é chamado a se pronunciar e assim se agiganta em busca de respostas rápidas a todos os conflitos. Entretanto, o acesso absoluto e irrestrito ao Judiciário diante da judicialização da política, da saúde, da vida privada e das mais diversas e variadas contendas diárias individuais, coletivas ou difusas, seja no 
âmbito social, econômico e até religioso acaba por prejudicar a execução da atividade jurisdicional, embora não se possa afirmar que essa é a única razão para o estrangulamento da capacidade da função judicial, mas é certo ser um obstáculo à a duração razoável do processo e a efetividade das decisões provocando, dessa forma, a disfuncionalidade do sistema de acesso à garantia de direitos fundamentais.

É certo que diante das especificidades cotidianas de uma sociedade metamorfoseante é preciso reposicionar o fenômeno jurídico e político neste cenário de novas exigências para o desenvolvimento humano, econômico e social, pois diante do crescimento das demandas judicionalizadas é cada dia mais frequente os discursos de reforma do judiciário para adoção de filtros judiciais em face da inviabilização quantitativa e qualitativa de responder ao incessante ingresso de demandas, podendo ser citado as reformas de procedimentos judiciais e as alternativas de solução extrajudicial, as quais muitas delas eficientes e adequadas, mas ainda a efetividade é reduzida diante da crise de sustentabilidade do sistema.

Entre as alternativas que surgem no cenário jurídico figura-se a criação dos Juizados Especiais pelas leis $\mathrm{n}^{\circ} 9.099$ (BRASIL, 1995), $\mathrm{n}^{\circ} 10.259$ (BRASIL, 2001) e $\mathrm{n}^{\circ} 12.153$ (BRASIL, 2009), a prévia conciliação judicial prevista pela Resolução ${ }^{\circ} 125$ do Conselho Nacional de Justiça (BRASIL, 2010) com a criação de núcleos de conciliação e agora com a exigência da audiência prévia de conciliação conforme determina o artigo 334 da Lei no 13.105 (BRASIL, 2015a), destacando-se ainda diversos institutos de extrajudicialização a exemplo da usucapião administrativa, a consolidação da propriedade na alienação fiduciária e a retificação de área de propriedade, ambos de bens imóveis entre outros.

Outro importante instituto da desjudicialização é a arbitragem regulada pela Lei n ${ }^{\circ} 9.307$ (BRASIL, 1996), alterada pela Lei $\mathrm{n}^{\circ} 13.129$ (BRASIL, 2015b), tratando-se de uma solução alternativa, mas de pouca cultura no meio social na utilização desse método, restando em geral adstrito a discussões econômicas e patrimoniais de grande vulto e notadamente entre empresas.

A Lei $n^{\circ} 13.140$ (BRASIL, 2015c) alterando a Lei nº 9.307 de Mediação e Arbitragem (BRASIL, 1996) contemplou a possibilidade da utilização desse instituto nos conflitos envolvendo a Administração Pública Direta e Indireta de quaisquer poderes, pelo qual discute-se então a possibilidade, por meio das Câmaras de Prevenção e Resolução de Conflitos, de serem regulamentadas no âmbito das administrações públicas permitir aos interessados a discussão prévia de matérias objeto de conflito em outra esfera que não o Judiciário.

Como se verifica, tentativas de soluções parecem viáveis diante desse principal problema do Judiciário e os institutos de desjudicialização vêm sendo trabalhado pelas vias legislativas e administrativas, tudo com o escopo de atender os objetivos fundamentais da preconizados na Carta Republica de construção de uma sociedade livre, justa e solidária (BRASIL, 1988, art. $3^{\circ}$ ).

\subsection{O Devido Processo Legal Constitucional}

A Constituição da República Federativa do Brasil de 1988 tem como direito fundamental 
para a proteção e efetivação dos direitos o acesso irrestrito à justiça, conferindo constitucionalidade às ações na esfera individual e também coletiva, pelo que a exigência de efetividade dos direitos se traduz como norma de aplicação imediata a fim de garantir a proteção dos direitos fundamentais, devendo, portanto, o processo jurisdicional ser o instrumento de transformação da realidade social mediante as ações concretas que o intérprete legitimado vier a adotar.

Nota-se que os direitos fundamentais positivados no texto constitucional, e a sua proteção, devem ser trabalhados a partir de um novo conceito ressignificado de liberdade positiva e exigem não somente ações prestacionais do Estado para atendimento das promessas constitucionais no tocante aos direitos sociais, mas coloca o cidadão na condição de titular e destinatário do poder o que requer, portanto, observância da defesa e garantias de direitos fundamentais por parte de todas as esferas de poder estatal.

Diante da eficácia irradiante da normatividade constitucional o exercício do poder antes autoritário e centrado na Supremacia da Administração passa a legitimar-se nas democracias fundadas no poder genuíno do cidadão como titular desse poder, firmando a constitucionalização do Direito sob a perspectiva do devido processo constitucional.

A construção judicial do direito por meio do Processo é um compromisso entre a estabilidade e a evolução e, portanto, a função do processo deve ser instrumento de mudança da qual resulte segurança na realização dos interesses envolvidos.

A Teoria Geral do Processo é considerada como exposição de conceitos, instituições e princípios comuns aos distintos ramos do processo, sendo que a Constituição determina muitos dos institutos básicos do processo, restando estreitas as ligações entre a Constituição e o Processo, pelo que os direitos fundamentais vêm sendo usados recorrentemente na jurisprudência e doutrina.

Nesse contexto, e partindo-se da premissa de que o direito de ação enquanto instrumento de defesa e garantia de direitos previsto no capítulo de Direitos Fundamentais da Constituição é mais amplo e requer também uma nova leitura por meio da processualidade alargada, pode-se afirmar que não se pode prescindir do devido processo constitucional.

A terminologia acesso à justiça é usualmente empregada como a finalidade básica do sistema jurídico pelo qual o cidadão possa reivindicar seus direitos e resolver os conflitos mediante a intervenção do Estado, mas também se traduz no funcionamento de um sistema acessível a todos e ao final pode ser firmado como um direito fundamental o qual deve ser garantido pelas funções estatais na busca de se promover a igualdade material e jurídica mediante resultados justos.

Leonardo Carneiro da Cunha nos lembra:

Uma das maiores preocupações da doutrina é com a diminuição do tempo do processo e, de resto, com a efetividade processual. Já se constituiu jargão afirmar que justiça tardia não é justiça. Quando o texto constitucional assegura o livre acesso à justiça, está a garantir uma prestação jurisdicional efetiva e tempestiva, sem desgaste resultante das mazelas de uma insuportável demora na entrega da tutela jurisdicional [...] (CUNHA, 2012, p. 254). 
Nesse sentido a busca da igualdade e o equilíbrio entre a demanda, a prestação de serviço e a duração razoável do processo é o ponto central para a satisfação e efetividade na execução das atividades estatais diante das promessas constitucionais do Estado do bem-estar social.

A Constituição, no artigo $1^{\circ}$, inciso III assegura a dignidade da pessoa humana e no artigo $5^{\circ}$, inciso XXXV (BRASIL, 1988) assegura que a lei não excluirá da apreciação do Poder Judiciário lesão ou ameaça ao direito. Nessa senda, e em atendimento aos valores e princípios constitucionais, o artigo $1^{\circ}$ da Lei $\mathrm{n}^{\circ} 13.105$ - Código de Processo Civil (BRASIL, 2015a) determina que o processo será ordenado, disciplinado e interpretado conforme normas fundamentais estabelecidas na Constituição Federal de 1988.

Assim é que a legislação processual assegura inafastabilidade da tutela jurisdicional em seus art. $2^{\circ}$ e $3^{\circ} ;$ o direito à solução integral do mérito, incluindo a atividade satisfativa em um prazo razoável conforme o art. $4^{\circ}$; o desenvolvimento do processo consoante a boa-fé e a cooperação processual previstos nos art. $5^{\circ}$ e $6^{\circ}$; a equidade processual zelando pelo contraditório com paridade de armas na conformidade do art. $7^{\circ}$; a atenção aos postulados da dignidade da pessoa humana, proporcionalidade, razoabilidade, legalidade, publicidade e a eficiência contidos no art. $8^{\circ}$; do contraditório amplo e da proibição surpresa estatuídos pelos art. $9^{\circ}$ e 10 e que o processo seja resolvido mediante decisões fundamentadas na forma do art. 11, todos do Código de Processo Civil de 2015.

Nessa ordem o acesso à justiça ressignificado representa muito mais que a inafastabilidade jurisdicional prevista no artigo $5^{\circ} \mathrm{XXXV}$ da CRFB (BRASIL, 1988), mas materializa-se pela adequação do processo ao direito material, pela simplificação de formas e procedimentos, pela duração razoável do processo sem dilações indevidas e a racionalidade do sistema recursal, como também a valorização das ações coletivas e decisões individuais e socialmente justas.

\section{VIAS ALTERNATIVAS PARA A DEFESA DE DIREITOS FUNDAMENTAIS}

Pelas vias alternativas pode-se destacar como mencionado anteriormente a Arbitragem, a Mediação e a Conciliação, tratando-se, a primeira, de um método de jurisdição privada composto de técnicas de solução de conflitos no qual as partes consentem que o litígio seja resolvido por terceira pessoa, em regra de confiança e escolhida pelos próprios envolvidos, cuja normatividade acha-se estabelecida na Lei $n^{0} 9.307$ (BRASIL, 1996) alterada pela Lei $n^{\circ} 13.129$ (BRASIL, 2015b).

Nos artigos 165 a 175 do Código de Processo Civil (BRASIL, 2015a) encontra-se previsto os institutos da mediação e conciliação, havendo nesse processo um terceiro intermediário com o fim de conduzir ou facilitar o diálogo entre as partes em busca da autocomposição consensual.

A diferença reside em que na arbitragem estaremos diante de uma forma de heterocomposição do conflito, onde será o terceiro a decidir o litígio. Já conciliação e mediação serão as próprias partes que chegarão ao consenso, sendo que o conciliador atua preferencialmente nos casos em que não houver vínculo anterior entre as partes e propõe soluções. Na mediação ocorrerá nos casos em que já houver vínculo entre os envolvidos, mas não propõe nenhuma 
solução, apenas auxilia os interessados a compreender o conflito para que eles mesmos possam restabelecer a comunicação e cheguem à soluções viáveis para ambas as partes.

\subsection{Vias Alternativas Para A Implantação De Políticas Públicas}

Na mudança do Estado Absolutista para o Estado de Direito figurou o império da lei para a organização das atividades estatais sob o julgo da legalidade. Contudo em face da ressignificação do princípio da legalidade, que se viu convertida em juridicidade, o legislador continuou a criar leis. Porém esteve centrado em fixação dos fins e objetivos do Estado, passando o Executivo à implantação de meios, ficando encarregado da programação e planejamento para a concretização das finalidades traçadas no âmbito legislativo, ao que se nomina como políticas públicas e ao Judiciário reservado está o controle da implementação dessas políticas.

Portanto, compreendendo políticas públicas como programas de ações governamentais com vistas à efetivação dos direitos fundamentais trazidos como princípios ou diretrizes constitucionais, pode-se afirmar que a inércia do Estado considerado em suas distintas funções estatais é violação do poder-dever estatal que subtrai direitos subjetivos do cidadão.

Luciana Gaspar Melquíades Duarte trazendo o conceito de política e função pública ensina:

Função política do Estado consiste na atividade atribuída a órgãos instituídos constitucionalmente para concretizar os valores maiores da nação e permitir a vida em comunidade. Tem por escopo preservar a sociedade política e promover o bem comum, através de determinação, mediante a interpretação de normas constitucionais, do que é o interesse público e de quais são os meios necessários à sua implementação (DUARTE, 2011, p. 68).

A autora, em complemento, assevera que a política consiste na atividade cuja essência é a distribuição dos recursos disponíveis na sociedade de acordo com as escolhas realizadas pelo Estado previamente limitadas pelas normas constitucionais e buscando conceituar política pública acrescenta:

[...] A política pública é, do ponto de vista da ciência política, um conjunto de ações e omissões que manifestam uma modalidade de intervenção do Estado como resultado do conflito de interesses divergente, confrontos e negociações entre várias instâncias instituídas ou arenas e entre os atores que dela fazem parte, caracterizando formas de ação governamental aptas a alcançar finalidades públicas e a implementar, portanto, os propósitos do Estado do Bem-Estar Social. (DUARTE, 2011, p. 71).

A frequente provocação do judiciário para o controle de políticas públicas é o retrato da má elaboração das políticas ou de juízos de ponderação mal processados pelos poderes por elas responsáveis, sendo recorrente a utilização do judiciário para atendimento da demanda por promessas constitucionais reclamadas por meio dos institutos processuais de tutela coletiva para 
proteção de direitos ou interesses difusos, coletivos, individuais homogêneos. Inclui-se, ainda, os direitos individuais indisponíveis, pois seja a coletividade, a comunidade representada por grupos, classes ou categorias de pessoas, ou mesmo os indivíduos considerados em conjunto, em razão da lesão ao bem jurídico de origem comum e, mesmo que seja uma única pessoa, mas que diante de sua hipossuficiência ou hipervulnerabilidade reclama a prestação estatal, em razão do direito fundamental ressignificado de acesso à justiça, deve o sistema estar dotado de mecanismos jurídicos para implantar políticas públicas inexistentes, incrementar as deficientes e modificar as ineficientes.

É pela via da tutela coletiva que os destinatários das políticas públicas exercitam a sua voz para reclamar as obrigações prestacionais do Estado e, portanto, esses devem ser consultados, pois conforme Eduardo José da Fonseca Costa a política pública sem a participação da população é antidemocrática (COSTA, 2012, p. 112).

Fredie Didier e Hermes Zaneti, nessa linha de ideias, escrevem sobre um modelo participativo para implementação e participação de políticas públicas que permite a um só tempo o conhecimento colaborativo do problema pelas partes e pelo juiz, somado de uma maior responsabilização e legitimação da decisão:

A complexidade da matéria envolvida na implementação e aplicação de políticas públicas força a migração de um modelo meramente responsivo e repressivo do Poder Judiciário, modelo de atuação posterior aos fatos já ocorridos, para um modelo resolutivo e participativo, que pode anteceder aos fatos lesivos e resulta na construção de soluções jurídicas adequadas. Essa mudança está amplamente amparada pela ótica do Processo Civil do Estado Democrático Constitucional adotada pelo $\mathrm{CPC},[\ldots]$ através do qual o juiz abre mão da centralidade do processo, reconhecendo a complexidade do problema da escolha das medidas necessárias, trazendo para o processo ampla participação de todos os envolvidos [...]. (DIDIER Jr.; ZANETI Jr., 2017, p. 38-39).

As decisões judiciais de cumprimento de políticas públicas são em regra materializados em obrigações de fazer contra a Fazenda Pública. Contudo a definição, programação, planejamento e execução das medidas prestacionais estão a cargo do Executivo que se abriga sob o manto da discricionariedade, residindo nesse ponto a problemática do ativismo ou da autocontenção judicial em fazer cumprir as decisões em sede de Ações Judiciais e que resvalam na cláusula pétrea da separação de poderes do artigo 60, § 4º, III da CRFB de 1988 (BRASIL, 1988).

Acerca da investigação do mérito dos atos administrativos no controle jurisdicional sobre os Atos da Administração Pública e a separação de poderes escreve Saulo Versiane Penna:

A clausula da "reserva do possível", portanto, deve ser desmistificada, da mesma forma que a da "separação de poderes" ou de investigação judicial de "mérito" do ato administrativo, já que, sob o paradigma constitucional-democrático, somente se sustenta por intermédio da processualidade (devido processo legal) que garante à sociedade efetiva participação nos negócios do Estado (de interesse público) (PENNA, 2011, p. 297). 
Outro obstáculo para a devida prestação jurisdicional no tocante às políticas públicas são as formas de execução forçada ou coercitiva previstas em lei para fazer cumprir as decisões judiciais e, não são poucas as condenações do Estado em que medidas voltadas a compelir o agente público a implantar políticas públicas se vêm esvaziadas de eficácia, restando, portanto, insuficientes a imposição de multas para o fim que se destina, que nada mais é que compelir o Administrador recalcitrante ao acatamento da política pública determinada em sede de controle jurisdicional.

A implementação de uma política decorrente de decisão judicial se faz na forma do artigo 536 do Código de Processo Civil e, pelo artigo 537 cabe ao Juiz fixar um prazo razoável para o seu cumprimento pelo Poder Público com a possibilidade da imposição de astrent, não se descurando o magistrado do rol exemplificativo de medidas de apoio que se acham no $\S 1^{\circ}$ do art. 536, tudo com vistas à efetivação da tutela específica ou a obtenção do resultado prático equivalente (BRASIL, 2015a).

Como se verifica esses são meios essencialmente coercitivos, contudo não obstante a aplicação desses dispositivos à Fazenda Pública para o cumprimento de obrigações de fazer, não é raro a inefetividade do provimento jurisdicional, acarretando a insatisfação dos interessados diretos e ao Juiz restando a indignação.

Sobre a efetivação das decisões judiciais no cumprimento de políticas públicas Daniel Amorim Assunção Neves também escreve:

Por fim, é preciso registrar a extrema dificuldade de se efetivar decisões judiciais que determinam a implantação de políticas públicas. Naturalmente tratando-se de obrigação de fazer ou não fazer, serão aplicáveis todos os meios executivos indiretos e de sub-rogação, nos termos dos artigos 139 , IV e 536, § $1^{\circ}$, ambos do Novo CPC. Ao agente recalcitrante também se poderá aplicar a multa prevista no art. $77, \S 2^{\circ}$, do Novo CPC em razão do nítido caráter atentatório da dignidade da justiça da conduta (NEVES, 2016, p. 119-120).

Comportaria medidas mais gravosas para se fazer atendida a ordem judicial a exemplo da prisão por crime de desobediência previsto no artigo 330 do Código Penal Brasileiro (BRASIL, 1940), a responsabilização do ato de improbidade tipificado a conduta no artigo 11 da Lei no 8.429 (BRASIL, 1992) e a intervenção nos Estados e Municípios e também a intervenção judicial no órgão público previstas nos artigos 34 e 35 da CRFB (BRASIL, 1988). Contudo não se afiguram eficazes para o que se pretende, que é a implantação da política pública prestacional.

A uma porque a imposição de multa ao agente recalcitrante restará multiplicada pelos reiterados descumprimentos e ao final a soma vultuosa recairá sobre os cofres públicos atingindo os cidadãos contribuintes, a duas porque o delito de desobediência do artigo 330 do Código de Penal requer dolo e a prisão do administrador é o que menos interessa à sociedade, visto que medida gravosa como essa, não irá adiantar a implantação da medida judicial e na maioria das vezes acabará por tumultuar o processo, pelo que entende-se que a execução forçada por meio do 
encarceramento não é o meio mais eficiente.

De igual forma, para a caracterização da infração civil do artigo 11 da Lei no 8.429 de 02 de junho de 1992 (BRASIL, 1992) requer-se a demonstração do dolo ainda que genérico. Por sua vez a intervenção federal nos Estados ou a intervenção estadual nos municípios em face dos artigos 34, VI e 35, IV da CRFB (BRASIL, 1988) respectivamente, são cabíveis somente quando há descumprimento voluntário ou injustificado da decisão judicial.

Ademais a intervenção judicial em Órgãos Públicos que seja para simples verificação ou a cogestão ou até mesmo a substituição do Administrador com ou sem o afastamento do gestor público revela-se complexa e temerária, como também o próprio interventor encontrará tormentosas dificuldades para implantação desta e não daquela outra política pública.

Destarte, o descumprimento de políticas públicas poderá ocorrer por variadas razões, sejam por limitações orçamentárias, recursos públicos escassos, ações e obras emergenciais e outras tantas agravuras na gestão da coisa pública que pode inviabilizar ou dificultar o atendimento da decisão judicial. Ademais, o atendimento de políticas públicas é ato complexo e que envolve variadas secretarias, setores, agentes e órgãos diversos a depender da natureza e abrangência da ação programática para o planejamento, preparação e execução do que ora se pretende, não podendo, contudo, sob a pretensa alegação da reserva do possível que a Administração relegue o cumprimento de decisões judiciais, como realça Daniel Amorim Assunção Neves:

Registre-se, inclusive, que o Supremo Tribunal Federal não admite como defesa da Administração Pública a alegação da "reserva do possível," o que justificaria, diante da insuficiência de disponibilidade financeira e orçamentária, proceder a verdadeiras "escolhas trágicas", o que levaria inevitavelmente a sacrifícios significativos de determinados valores e interesse. Segundo a Corte Constitucional, a cláusula da reserva do possível não pode ser utilizada para fraudar, frustrar ou inviabilizar a implementação de políticas públicas definidas na própria Constituição, considerando a garantia do mínimo existencial, derivado do princípio fundamental da dignidade da pessoa humana [...] (NEVES, 2016, p. 118-119, grifos no original).

De fato, é a Administração que detém a visão do todo na conjectura administrativa da máquina pública, cabendo ao Gestor escolher o meio, o modo, a técnica e o tempo para atender esse ou aquele outro interesse público, notadamente diante da insaciabilidade social quanto às exigências e carências dos direitos de $2^{\mathrm{a}}$ e $3^{\mathrm{a}}$ dimensão.

O cumprimento de uma obrigação de fazer em geral, em face da máquina burocrática administrativa, enseja adoção de procedimentos e atos administrativos que requerem cronogramas fracionados entre os atores envolvidos na prestação estatal e, nessa senda, os meios alternativos de solução de conflitos surgem como propostas para a busca da efetividade jurisdicional no atendimento à implementação de direitos fundamentais.

Esse também é o entendimento de Fredie Didier et al. (2017):

[...] o que autoriza a conclusão de que a criação de medidas executivas atípicas 
pode ser obra das próprias partes, e não apenas do juiz, numa harmoniosa combinação entre cláusulas gerais e cláusulas gerais de negociação do art. 190 do CPC. Também se admite, como se disse em item anterior, a execução negociada das decisões estruturais, sobretudo daquelas que determinam a implantação de política pública. Nesse caso, a convenção processual incluirá o julgador. (DIDIER Jr. et al., 2017, p.138).

Trata-se de celebração de cronogramas negociados de cumprimento voluntário das decisões judiciais, cuja solução irá prestigiar os princípios da boa fé, da cooperação e da adequação processual em atenção aos valores e fundamentos do ordenamento processual.

\section{A SOLUÇÃO JUDICIAL DIALOGADA PARA O CUMPRIMENTO DE POLÍTICAS PÚBLICAS}

O artigo $3^{\circ}, \S 3^{\circ}$ do Código de Processo Civil (BRASIL, 2015a) prevê a utilização dos métodos que privilegiem a solução consensual de conflitos, estabelecendo o legislador que a conciliação, mediação e outras técnicas, deverão ser estimuladas por Juízes, Ministério Público e Defensoria, inclusive no curso do Processo Judicial. Assim é dever do Estado-Juiz e EstadoAdministrador e também do Estado-Legislador buscar a solução ajustável à contenda.

Ademais o artigo 165 traz que os tribunais exercitarão as resoluções consensuais mediante a criação de centros judiciários de solução de conflitos, onde poderão ser realizadas sessões e audiências de conciliação e mediação, e com o desenvolvimento de programas destinados a auxiliar, orientar e estimular a autocomposição. Nesse descortino é que se vislumbra técnicas ou métodos alternativos de solução judicial dialogada com a participação do Poder Público e do destinatário das políticas públicos como forma a viabilizar a execução da decisão judicial e com a atuação conciliadora do magistrado.

Verifica-se, portanto que o procedimento de controle judicial de políticas públicas no dizer de Fredie Didier Júnior e Hermes Zaneti Júnior é complexo, delongado, vários são os limites orçamentários e inflexíveis são os controles burocráticos internos e externos a obstaculizar a Administração de desincumbir-se da sua importante função na forma, quantidade e tempo desejado pela população.

Contudo, com a edição da Lei no 13.140 (BRASIL, 2015c) que trata da mediação entre particulares como meio da solução das controvérsias e que inova permitindo a composição no âmbito da Administração Pública sobre direitos disponíveis e também direitos indisponíveis que admitam transações, incluindo a mediação coletiva envolvendo a não prestação ou a qualidade da prestação do serviço público, torna-se concreto a possibilidade da Administração no exercício da sua competência técnico-administrativa dirimir seus conflitos, avaliando composições amigáveis, com vistas a celebração de soluções dialogadas, sempre com o objetivo de se privilegiar as decisões pautadas na boa fé, na ética e na lealdade processual, com vistas ao consenso nas negociação e na ponderação dos interesses envolvidos.

Luiz Manoel Gomes Júnior já em época outrora inclinava-se a defender a possibilidade de 
haver transações em Ações Coletiva, achando-as por viável a exemplo de negociar-se ampliação de prazo para o cumprimento da obrigação, ou mesmo a alteração do modo do seu cumprimento (GOMES JÚNIOR, 2005, p. 167).

Antes disso, Rodolfo de Camargos Mancuso (MANCUSO, 2002, p. 247-248 apud GOMES JÚNIOR, 2005, p. 168) já entendia nessa conformidade, contudo ressaltava da inconveniência em se alargar por demasia as alternativas e acrescia:

[...] preferível um a solução negociada, que se mostre idônea e eficaz para resolver o conflito gerado pela lesão ou ameaça ao interesse indigitado, do que uma obstinada busca pela solução judicial, que pode ser demorada, onerosa e, algumas vezes de difícil previsibilidade quanto ao seu desfecho (GOMES JÚNIOR, 2005, p. 168).

Eduardo José da Fonseca Costa (2012) nomina a intervenção judicial para a implantação de políticas públicas de "execução negociada" e explica a sua escolha para a denominação, pois execução propriamente não haverá, visto que o que se propõe é o cumprimento voluntário da busca da efetivação da decisão, onde a mediação judicial é uma via alternativa para a solução das controvérsias.

Entre as negociações que se apresentam possíveis diante do caso concreto, Fonseca Costa tece um rol exemplificativo como se vê:

Para que se consiga um cronograma negociado desse tipo, recomenda-se, entre outras coisas: i) que o juiz da causa se reúna as sós com cada uma das partes para ouvir suas posições, identificar interesses subjacentes comuns e contrapostos, simular algumas alternativas de acordo e interromper a audiência quando a conversação se mostrar hostil ou obstruída (na técnica da mediação, essa reunião privada é chamada de cáucus ); ii) a instauração de rodadas de negociação para a discussão dos temas e de cada uma das etapas do cronograma; iii) a presença, não apenas dos advogados, do Ministério Público e dos representantes legais dos entes envolvidos, mas também dos responsáveis técnicos encarregados internamente do cumprimento de cada etapa do cronograma; iv) a consulta eventual a terceiros especialistas - nomeados pelo juiz como peritos, ou intervenientes na qualidade de amici curiae - para a ampliação das informações imprescindíveis; v) a possibilidade democrática de participação não só das partes e dos auxiliares da justiça, mas dos setores da sociedade interessados na implantação da política pública, fazendo-se, assim, com que a relação processual assuma uma estrutura polifônica transponha a bilateralidade autor-réu (já que, no Estado Social e Democrático de Direito, construído para uma sociedade fragmentária e pluralista, as experiências institucionais conquistam maior legitimidade - de natureza tópica , sublinhe-se - à medida que se estruturam sob canais de controle e participação direta dos destinatários da ação governamental); vi) a possibilidade de os presentes usarem na audiência mapas, planilhas, gráficos, plantas, desenhos, estudos, rascunhos, orçamentos, croquis, vídeos, fotografias, retroprojetores, slides, quadros, lousas, telas para PowerPoint, propostas, comentários e toda sorte de recursos audiovisuais necessários à explanação técnica de suas perspectivas; vii) a possibilidade de eventual interrupção da audiência para a realização de 
inspeção judicial nos locais de instalação das estruturas que serão necessárias à implantação da política; viii) a reserva de um espaço amplo e informal para acolher com conforto os presentes, facilitar o diálogo entre eles e comportar toda a estrutura física acima sugerida (COSTA, 2012, p. 124).

Portanto, uma negociação da decisão judicial no âmbito do processo é uma medida que se apresenta viável, sendo que, por meio do procedimento executivo ou de cumprimento de sentença a conciliação seria construída pelas partes a partir de um negócio jurídico processual atípico na forma como autoriza os artigos 190 e 191 do Código de Processo Civil (BRASIL, 2015a).

Didier Júnior e Hermes Zaneti Júnior apontam que em se tratando de implantação de políticas públicas, a decisão judicial que a determina estará contida em uma obrigação de fazer, regida pelo Código de Processo Civil e, dessa forma, consagrado está a atipicidade da execução conforme o $\S 1^{\circ}$ do art. 536 e, pelo art. 139, IV ampliado poderá ser os poderes do juiz com o escopo da efetivação das decisões judiciais, possibilitando assim uma execução negociada na qual o procedimento será construído pelas próprias partes (DIDIER JR.; ZANETI JR., 2017, p. 482).

Uma execução ou cumprimento das partes pela qual possa se estabelecer acordos e calendários processuais, onde a definição de um cronograma de cumprimento da decisão judicial será elaborado pelas próprias partes e já com definição de etapas para a implantação da política pública mediante a previsão do tempo necessário, das formas para a supervisão e medidas moratórias para eventual retardamento total ou parcial do descumprimento.

Nesse compasso a solução judicial dialogada propõe a interação entre as partes do processo, no qual o cronograma poderá ser ajustado com compromissos factíveis e marcos temporários reais, onde o Estado-Juiz não estará para compelir o cumprimento na rigidez ou imposição da decisão judicial, mas sim voltado ao comprometimento com o interesse público, incitando o diálogo, relativizando as amarras judiciais e burocráticas da máquina administrativa, privilegiando a criatividade das partes envolvidas, flexibilizando os prazos e revisando os acordos a cada etapa cumprida.

Pode-se concluir que essa medida alternativa é viável, notadamente se desenvolvida por agentes públicos vocacionados, com inteligência transdisciplinar e juízes comprometidos com a efetividade da prestação jurisdicional e a satisfação do interesse da coletividade.

Necessário a complementação de que a possibilidade da composição de conflitos via solução judicial negociada ocorrerá na forma da proteção e garantia do direito processual constitucional, com a presença das partes em diálogo aberto e constante, pela cooperação e eticidade e, nessa plêiade de possibilidades para a efetivação das políticas públicas é a solução judicial dialogada uma via alternativa, legal e hábil como técnica e método do devido processo constitucional, medida essa necessária, urgente e esperada em contraposto à excessiva judicialização das políticas públicas e os entraves para a prestação jurisdicional efetiva.

Por essa razão tem esse trabalho de pesquisa o escopo da promoção do debate científico a fim de se sensibilizar juízes, gestores públicos, comunidade acadêmica, jurídica e doutrinaria para a disseminação da necessidade de adoção de vias alternativas de solução consensual de conflitos 
com vistas a adoção das soluções judiciais dialogadas, implantando-se a cultura de resolução dos seus conflitos por meio da revisitação do paradigma da supremacia da Administração e da superação do postulado da indisponibilidade do interesse público.

Nesse sentido a solução judicial negociada se desponta como via alternativa para a garantia do atendimento ao interesse público e proteção dos direitos fundamentais, sendo preciso ressaltar que as vias alternativas para a solução de conflitos são técnicas enquanto processo para garantia dos direitos fundamentais ou são métodos enquanto instrumentos do devido processo constitucional. Seja técnica e/ou método, o que não se pode prescindir é do processo enquanto via de acesso à inafastabilidade da justiça, haja vista os prejuízos e déficits no retardamento ou não cumprimento das políticas públicas prestacionais.

\section{CONSIDERAÇÕES FINAIS}

A ampliação da jurisdição constitucional tornada concreta pelo neoconstitucionalismo coloca o judiciário na centralidade do exercício de poder e, reforçada pelo protagonismo judicial, torna essa função estatal a mola propulsora do alcance da eficácia dos direitos fundamentais.

A inefetividade ou inexistência de ações programáticas para a implantação de programas governamentais de atendimento aos anseios e necessidades da população acarreta violações de direitos para o cidadão destinatário final da função administrativa, visto a caracterização constitucional dos direitos de $2^{\mathrm{a}}$ e $3^{\mathrm{a}}$ dimensão, dotados de eficácia plena e aplicação imediata, ficando explicando, portanto o fenômeno da judicialização da política com o escopo de ser executado pelo Judiciário como instrumento de garantia da justiça retributiva, resolutiva e participativa

A atividade jurisdicional diante da ressignificação do acesso à justiça se vê no exercício do controle judicial da administração pública mediante a fiscalização e determinação de cumprimento das prestações de obrigação de fazer sem, contudo, violar a separação de poderes, uma vez que o Poder é uno e a jurisdição consensual exercida por meio do devido processo constitucional é mais uma forma em busca de soluções dialogadas e efetivas.

Assim com o fim de demonstrar a possibilidade de se firmar a solução judicial dialogada como via alternativa para proteção de direitos fundamentais a conclusão que se chega é a necessidade da revisitação na forma como o Estado-Juiz e Estado Administração na execução de suas atividades fins podem contribuir para a resolução consensual das complexas demandas de atendimento das prestações estatais.

É necessário o abandono summa divisio direito público e direito privado, da separação estanques de poderes, da premissa de indisponibilidade do interesse públicos e da Supremacia da Administração, visto que no Estado Democrático Contemporâneo o centro é o cidadão considerado na via coletiva ou individual, não mais prevalecendo a intransponível indisponibilidade do interesse público pela relação de desigualdade e subordinação dos administrados.

O devido processo constitucional como garantia do cidadão tem seus objetivos e métodos ampliados e alargam as suas funções mediante a participação dos destinatários de seus efeitos 
com oportunidade de dizer, contradizer, ajustar, flexibilizar e encontrar soluções dialogadas e equilibradas para o cumprimento das decisões judiciais, daí esse método se desponta e se firma como uma via hábil e eficiente para proteção dos indivíduos mediante o um procedimento consensual de resolução das demandas de políticas públicas.

Dessa forma, e esperando haver contribuído para a reflexão sobre a temática da implementação de políticas públicas por meio do controle jurisdicional, espera-se que novas propostas aflorem no meio jurídico e doutrinário, sabendo certo, bem como não era essa a pretensão, do não esgotamento do assunto, tendo em vista que se trata de uma discussão que carece de complementação em face de sua importância e universalidade para a proteção dos direitos fundamentais.

\section{REFERÊNCIAS}

ALMEIDA, Gregório Assagra. Direito material coletivo: superação da summa divisio direito público e direito privado por uma nova summa divisio constitucionalizada. Belo Horizonte: Del Rey, 2008.

BARROSO, Luiz Roberto. Neoconstitucionalismo e Constitucionalização do Direito (o triunfo tardio do Direito Constitucional no Brasil). Revista Eletrônica sobre a Reforma do Estado (RERE), Salvador, Instituto Brasileiro de Direito Público, n. 9, mar./abr./maio, 2007. Disponível em: http://www.direitodoestado.com/revista/RERE-9-MAR\%C7O-2007-LUIZ\%20ROBERTO\%20 BARROSO.pdf. Acesso em: 08 out. 2016.

BRASIL. Conselho Nacional de Justiça. Resolução $\mathbf{n}^{\mathbf{0}}$ 125, de 29 de novembro de 2010. Dispõe sobre a Política Judiciária Nacional de tratamento adequado dos conflitos de interesses no âmbito do Poder Judiciário e dá outras providências. Disponível em: http://www.cnj.ju s.br/busca-atosadm?documento=2579. Acesso em: 06 nov. 2017.

BRASIL. Constituição (1988). Constituição da República Federativa do Brasil. Brasília, DF, 5 out. 1988. Lex: legislação federal e marginalia. Disponível em: http://www.planalto.gov .br/ ccivil_03/constituicao/constituicao.htm. Acesso em: 06 nov. 2017.

BRASIL. Decreto-lei no 2.848, de 07 de dezembro de 1940. Código Penal Brasileiro. Diário Oficial [da] República Federativa do Brasil, Brasília, 31 dez. 1940. Disponível em: http:/ / www.planalto.gov.br/ccivil_03/decreto-lei/Del2848compilado.htm . Acesso em: 06 nov. 2017.

BRASIL. Lei no 8.069, de 13 de julho de 1990. Dispõe sobre o Estatuto da Criança e do Adolescente e dá outras providências. Diário Oficial [da] República Federativa do Brasil, Brasília, 16 jul. 1990. Disponível em: http:/ /www.planalto.gov.br/ccivil_03/decreto-lei/ Del2848compilado.htm . Acesso em: 12 nov. 2017.

BRASIL. Lei no 8.429, de 02 de junho de 1992. Dispõe sobre as sanções aplicáveis aos agentes públicos nos casos de enriquecimento ilícito no exercício de mandato, cargo, emprego ou função na administração pública direta, indireta ou fundacional e dá outras providências. Diário Oficial [da] República Federativa do Brasil, Brasília, 3 jun. 1992. Disponível em: http://www.planalto. gov.br/ccivil_03/leis/L8429.htm. Acesso em: 06 nov. 2017. 
BRASIL. Lei no 9.099, de 26 de setembro de 1995. Dispõe sobre o Juizado Especial Civil e Criminal. Diário Oficial [da] República Federativa do Brasil, Brasília, 27 set. 1995. Disponível em: http://www.planalto.gov.br/ccivil_03/leis/L9099.htm. Acesso em: 06 nov. 2017.

BRASIL. Lei no 9.307, de 23 de setembro de 1996. Dispõe sobre a arbitragem. Diário Oficial [da] República Federativa do Brasil, Brasília, 24 set. 1996. Disponível em: http://www.p lanalto.gov.br/ccivil_03/leis/L9307.htm. Acesso em: 04 nov. 2017.

BRASIL. Lei $\mathrm{n}^{\circ}$ 10.259, de 12 de julho de 2001. Dispõe sobre a instituição dos Juizados Especiais Cíveis e Criminais no âmbito da Justiça Federal. Diário Oficial [da] República Federativa do Brasil, Brasília, 13 jul. 2001. Disponível em: http://www.planalto.gov. br/ ccivil_03/leis/LEIS_2001/L10259.htm. Acesso em: 06 nov. 2017.

BRASIL. Lei $n^{\circ} 10.741$, de $1^{\circ}$ de outubro de 2003. Dispõe sobre o Estatuto do Idoso e dá outras providências. Diário Oficial [da] República Federativa do Brasil, Brasília, 3 out. 2003. Disponível em: http://www.planalto.gov.br/ccivil_03/leis/2003/L10.741.htm. Acesso em: 04 nov. 2017.

BRASIL. Lei no 12.153, de 22 de dezembro de 2009. Dispõe sobre o Juizado Especial da Fazenda Pública. Diário Oficial [da] República Federativa do Brasil, Brasília, 23 dez. 2009. Disponível em: http://www.planalto.gov.br/ccivil_03/_ato2007-2010/2009/lei/112153.htm. Acesso em: 06 nov. 2017.

BRASIL. Lei no 13.105, de 16 de março de 2015. Código de Processo Civil. Diário Oficial [da] República Federativa do Brasil, Brasília, 17 mar. 2015a. Disponível em: http://www.pl analto. gov.br/ccivil_03/_ato2015-2018/2015/lei/113105.htm. Acesso em: 06 nov. 2017.

BRASIL. Lei $\mathrm{n}^{\circ} 13.129$, de 26 de maio de 2015. Altera a Lei $\mathrm{n}^{\circ} 9.307$, de 23 de setembro de 1996, e a Lei no 6.404, de 15 de dezembro de 1976, para ampliar o âmbito de aplicação da arbitragem e dispor sobre a escolha dos árbitros quando as partes recorrem a órgão arbitral, a interrupção da prescrição pela instituição da arbitragem, a concessão de tutelas cautelares e de urgência nos casos de arbitragem, a carta arbitral e a sentença arbitral, e revoga dispositivos da Lei $n^{\circ}$ 9.307, de 23 de setembro de 1996. Diário Oficial [da] República Federativa do Brasil, Brasília, 27 maio 2015b. Disponível em: http://www.planalto.gov.br/ccivil_03/_Ato 20152018/2015/Lei/L13129.htm. Acesso em 06 nov. 2017.

BRASIL. Lei $\mathrm{n}^{\circ} 13.140$, de 26 de junho de 2015. Dispõe sobre a mediação entre particulares como meio de solução de controvérsias e sobre a autocomposição de conflitos no âmbito da administração pública. Diário Oficial [da] República Federativa do Brasil, Brasília, 29 jun. 2015c. Disponível em: http://www.planalto.gov.br/ccivil_03/_ato2015-2018/2015/Lei/L1314 0.htm. Acesso em: 06 nov. 2017.

COSTA, Carlos Eduardo da Fonseca. A $\square$ execução negociada $\square$ de políticas públicas em juízo. Revista do Ministério Público do Estado do Rio de Janeiro, Rio de Janeiro, n. 59, p. 109-136, jan./mar. 2012. Disponível em: https://bdjur.stj.jus.br/jspui/handle/2011/106801. Acesso em: 05 nov. 2017.

CUNHA, Leonardo José Carneiro da. A fazenda pública em juízo. 10. ed. São Paulo: Dialética. 2012. 
DIDIER Jr., Fredie; ZANETI Jr., Hermes. Curso de direito processual civil: processo coletivo. 11. ed. Salvador: JusPodivm, 2017. v. 4.

DIDIER Jr., Fredie; CUNHA, Leonardo Carneiro da; BRAGA, Paulo Sarna. OLIVEIRA, Rafael Alexandria. Curso de direito processual civil: execução. 7. ed. Salvador: JusPodivm, 2017. v. 5.

DUARTE, Luciana Gaspar Melquíades. Possibilidades e limites do controle judicial sobre as políticas públicas de saúde: um contributo para a dogmática do direito à saúde. $\mathrm{BH}$, Fórum, 2011.

GOMES JÚNIOR, Luiz Manoel. Curso de direito processual coletivo. Rio de Janeiro: Forense, 2005.

MARANHÃO, Clayton. O Controle Jurisdicional de Políticas Públicas. In: GOZZOLI, Maria Clara; PETRONIO, Mirna Ciani; QUARTIERI, Rita (coord.). Em defesa de um novo sistema de processos coletivos: estudos em homenagem à professora Ada Pelegrini Grinover. São Paulo: Saraiva. 2010. p. 167.

MORAIS, José Luiz Bolzan de. As crises do estado e da constituição e a transformação espaço temporal dos direitos humanos. 2. ed. Porto Alegre: Livraria do Advogado, 2011.

MORAIS. José Luiz Bolzan de.; BRUM, Guilherme Valle. Políticas públicas e jurisdição constitucional: entre direitos, deveres e desejos, Estado e Constituição. 16. ed. Porto Alegre: Livraria do Advogado, 2016.

NEVES, Daniel Amorim Assumpção. Manual de processo coletivo. volume único. 3. ed. Salvador: JusPodvun, 2016.

PENNA, Saulo Versiani. Controle e implementação processual de políticas públicas no Brasil. Belo Horizonte: Forum, 2011.

PINHEIRO, Maria Claudia Bucchianeri. A constituição de Weimar e os direitos fundamentais sociais: a preponderância da Constituição da República Alemã de 1919 na inauguração do constitucionalismo social à luz da Constituição mexicana de 1917. Revista de informação legislativa, Brasília, DF, v. 43, n. 169, p. 101-126, jan./mar. 2006.

SHIMURA, Sérgio. O Reexame necessário nas Ações Coletivas. In: GRINOVER, Ada Pelegrini; MENDES, Aluísio Gonçalves de Castro; WATANABE, Kazuo (org.). Direito processual coletivo e o anteprojeto de código brasileiro de processos coletivos. São Paulo. Revista dos Tribunais. 2007. p. 345.

ZAVASCKI, Teori Albino. Processo coletivo: tutela de direitos coletivos e tutela coletiva de direitos. 7. ed. São Paulo: Revista dos Tribunais, 2017.

Como citar: LEMOS JUNIOR, Eloy Pereira; QUADROS, Aparecida Dutra de Barros. A implantação de políticas públicas pela solução judicial dialogada. Revista do Direito Público, Londrina, v. 14, n. 3, p. 11-34, dez. 2019. DOI: 10.5433/24157-108104-1.2019v14n3p. 11. ISSN: $1980-511 \mathrm{X}$ 
Recebido em: 26/06/2017

Aprovado em: 28/01/2019 